\title{
LA FRONTERA NORORIENTAL Y ORIENTAL DEL DISTRITO ANDALUSÍ DE LLEIDA (SS. X-XI)
}

\author{
Jesús Brufal i Sucarrat ${ }^{1}$
}

\section{RESUMEN}

La frontera nororiental y oriental del distrito andalusí de Lleida se configura a partir del siglo IX y se rompe a principios del siglo XI, prácticamente coincidiendo con la fitna de 1010. Este vasto territorio se organiza a partir de los cursos fluviales y las llanuras fértiles bien antropizadas como la correspondiente al ager de Guissona (Iesso). Estas realidades geográficas e históricas en forma de herencia territorial clásica, se vertebran desde una perspectiva andalusí, de aquí la instalación de comunidades rurales cerca de los cursos fluviales, la construcción de fortalezas como Calaf, la presencia de ribats en sus proximidades y, se garantiza la comunicación terrestre resiguiendo los valles fluviales o vías de comunicación, también, preexistentes.

Palabras clave: Frontera andalusí, fortalezas, cursos fluviales, vías de comunicación, comunidades rurales.

\begin{abstract}
The north eastern and eastern borders of the Andalusian district of Lleida were shaped from the $9^{\text {th }}$ century onwards and fractured during the early $11^{\text {th }}$ century, almost at the same time as the fitna or unrest of 1010 . This vast territory was organised around the river courses and the fertile flood plains which had long been anthropised, such as the ager or public land around Guissona (formerly Iesso). These geographical and historical realities formed a classical territorial legacy structured from an Andalusian perspective,

1 Profesor Lector Serra Húnter en el Departamento de Ciències de l'Antiguitat i de l'Edat Mitjana de la Universitat Autònoma de Barcelona.
\end{abstract}


thus the rural communities grew up alongside the river courses, with the construction of fortresses such as Calaf, the presence of ribats or forts in the surrounding area, and land communications were ensured, tracing the course of the river valleys or the pre-existing roads and thoroughfares.

Keywords: Andalusian borders, fortresses, river courses, roads, rural communities.

\section{INTRODUCCIÓN}

La frontera convive con el distrito andalusí de Lleida. En realidad, la identidad y la ideología de la ciudad leridana y su distrito, se convierten en factores que inciden en el establecimiento de fronteras ante la alteridad. La construcción identitaria e ideológica se sirve de la memória histórica como elemento cohesionador y legitimador. Fruto de lo anterior nacen conceptos vinculados con ser lo contrario -desde el siglo noveno con sociedades cristianas organizadas y vertebradas por el feudalismo y la Iglesia romana-, o el adversario -mirando hacia el interior de al-Ándalus, las disputas entre grupos tribales rivales, han fosilizado fronteras entre distritos que albergan ambas comunidades.

Éste ámbito de relaciones genera un marco de convivencia entre los unos y los otros ${ }^{2}$, y a su vez incide en la configuración de un paisaje que les da respuesta. Así pues, en el siglo noveno el emirato cordobés destina esfuerzos para vertebrar y organizar una frontera fuerte y ancha en ambas riberas del río Ebro, a raíz de la pujanza carolingia de finales del siglo octavo e inicios del noveno. En éste gran proyecto fronterizo, Zaragoza vehicula los esfuerzos de capitalidad del emirato cordobés, aunque es objeto de deseo del linaje muladí de los Banū Qasī, con la intención de vertebrar sus propios espacios de relación e influencia ${ }^{3}$. Como tal, es la encargada de configurar un amplio espacio urbano en toda la Frontera Superior, de aquí que la ciudad de Lleida de tradición tardoantigua, se inserta plenamente en el organigrama administrativo y social andalusí, y organiza su propio distrito con una clara vocación fronteriza y militar ${ }^{4}$. Precisamente, la inercia del emirato cordobés de controlar el ámbito urbano por mediación de gobernadores afines vinculados a linajes árabes como los Banū Tuğīb, entra en conflicto con los linajes muladíes (que a su vez entre ellos eran rivales) los Banū Qasī y los Banū Sabrīt que controlan como herencia de la tardoantigüedad gran parte del valle del

2 MARÍN NiÑO, M., Al-Ándalus y los andalusíes, Barcelona, 2000, pp. 62-64.

3 VIGUERA MOLINS, M.J., Aragón musulmán. La presencia del Islam en el Valle del Ebro, Zaragoza, 1988, pp. 75-140.

4 SABATÉ CURULL, F, Història de Lleida. Alta edat mitjana, vol. 2, Lleida, 2003, pp. 7-8. 
Ebro. El control del poder suscita disputas territoriales entre los distintos linajes muladíes y, al mismo tiempo, con tribus árabes.

La historiografía ha destinado numerosos esfuerzos en el estudio de la frontera leridana andalusí con los condados cristianos. Básicamente se han focalizado en el ámbito geográfico del Montsec, (actual pre-Pirineo de Lleida), delimitando el espacio de estudio por el este con el río Segre y por el oeste con el río Noguera Ribagorçana. Los análisis paisajísticos y los vaciados documentales inéditos de Fité $e^{5}$, Giralt ${ }^{6}$ y Sénac ${ }^{7}$ han suscitado interesantes propuestas e hipótesis de organización social y militar. A pesar de los numerosos estudios, la historiografía y los métodos de análisis han dado un salto cualitativo en treinta años ${ }^{8}$. Esto suscitó que era necesario reinterpretar los datos arqueológicos y documentales, y añadir nuevos datos en el proceso analítico. Los resultados y nuevas hipótesis se han elaborado en el marco de una tesis doctoral defendida recientemente ${ }^{9}$.

En cierto modo, la frontera se ha estudiado con más intensidad y detalle desde la vertiente condal, pues los datos documentales son más explícitos y generosos. Historiadores como Flocel Sabaté $e^{10}$ y Albert Benet ${ }^{11}$, han estudiado el proceso de conquista con detalle, obteniendo interesantes propuestas sobre la incidencia social de la conquista y la colonización del distrito leridano, asimismo la transformación del paisaje, el ideario político y espiritual, las fiscalidades y las jurisdicciones condales.

No obstante, a pesar de los numerosos estudios focalizados en la frontera del Montsec, fuera de ésta el estudio de la frontera no ha sido prioritario ni ha

5 FITÉ LLEVOT, F, Reculls d'Història de la Vall d’Àger. Període antic i medieval, Àger, 1985.

6 GIRALT BALAGUERÓ, J., "Arqueología andalusí en Balaguer (Lérida)", Sharq AlAndalus: Estudios mudejares y moriscos, 2, 1985, pp. 151-159.

7 SENAC, P., "Note sur les husūn de Lérida", Mélanges de la Casa de Velázquez, 24, 1988, p. 53-69.

8 SABATÉ CURULL, F., "Larqueologia medieval en entrar al segle XXI" en Arqueologia Medieval. Reflexions des de la pràctica, Lleida, 2007, pp. 9-19. BRUFAL, J., "Els reptes de l'arqueologia medieval en la tecnologia informàtica" en Arqueologia Medieval. Recerca avançada en arqueologia medieval, Lleida, 2013 (en premsa).

9 CORSÀ GARROFÉ, J., El poblament rural andalusí a les Aspres, nord del districteltaifa de Lleida (finals del segle X-principis del segle XII), tesi doctoral inèdita, Lleida, 2012.

10 SABATÉ CURULL, F., El territori de la Catalunya Medieval. Percepció de l'espai i divisió territorial al llarg de l'Edat Mitjana, Barcelona, 1997. SABATÉ CURULL, F., Atles de la "Reconquesta". La frontera peninsular entre els segles VIII i XV, Edicions 62, Barcelona, 1998. SABATÉ CURULL, F., "Frontera peninsular e identidad (siglos IX-XII)", Las cinco villas aragonesas en la Europa de los siglos XII y XIII, Esteban Sarasa Sánchez (Coord.), Zaragoza, 2007, pp. 47-93.

11 BENET CLARÀ, A., L'expansió del comtat de Manresa, Rafael Dalmau Editors, Barcelona, 1982. BENET CLARÀ, A., "La repoblació de la Segarra a l'alta edat mitjana (segles IX-XI), Palestra Universitària, 3, 1988, pp. 279-295. 
suscitado el interés de la historiografía, concretamente en el área nororiental y oriental del distrito andalusí de Lleida. El área de estudio la conocemos con mayor exactitud por mediación del proceso de conquista condal dentro el propio distrito leridano. De los datos que se obtienen del análisis de la documentación latina, se aprecian un buen número de asentamientos andalusíes de tipología diversa. El ager de la romana Aesso, hoy Guissona, desempeña una tarea articuladora, en confluir con los valles fluviales de los ríos Llobregós y Sió caudales para defender el Faḥs Maškiğăan, -actual Llano de Lleida. A pesar de la importancia que le otorgamos, los cronistas y geógrafos árabes no hacen referencia a la Aesso de tradición romana. En realidad, éstas fuentes árabes focalizan su interés en la capital, medina Lārida ${ }^{12}$, otras ciudades secundarias como Monzón, Balaguer y Fraga, y fortificaciones como Ağìra (actual Algerri), Montmagastre, Corbins ${ }^{13}$ (Qarabinn), entre otras de destacadas.

La herencia histórica del área de estudio nos llega con muchos silencios, pero a su vez suscitan interés, principalmente por los numerosos vestigios arqueológicos, toponímicos y la fosilización del paisaje andalusí. La presente investigación pretende dar luz a la organización de la frontera, resaltando el papel de los asentamientos agropecuarios y la ciudad ${ }^{14}$, la sociedad de frontera y la acción del emirato y califato Omeyas, para desembocar y entender la configuración de un paisaje social fronterizo en la Lleida andalusí de los siglos X y XI.

\section{DEFINICIÓN DE LA FRONTERA NORORIENTAL Y ORIENTAL DEL DISTRITO ANDALUSÍ DE LLEIDA}

Durante los primeros compases de la investigación, varias fueron las cuestiones principales que nos planteábamos con el propósito de entender ¿dónde empezaba la frontera en el distrito leridano y qué se entendía por frontera en el contexto histórico del emirato y el califato cordobeses? Ésta reflexión condujo a plantear qué ámbitos eran los óptimos para estudiar y entender el fenómeno de la frontera andalusí en el distrito leridano. De este modo, entendimos que el foco de interés se focalizaba en dos ámbitos concretos: el espacio fronterizo extremo del noreste y este leridano, y el distrito de Lleida como administración territorial de frontera.

12 LÉVI-PROVENÇAL, E., La Péninsule Ibérique au Moyen Age d'après le Kitāb ar-Rawd al-Mi'țār fi Habar al-Akțār. Ibn 'Abd al-Mun'im al-Himyarī, Leiden, 1936, p. 202.

13 BRAMON PLANES, D., De quan érem o no musulmans. Textos del 713 al 1010, Barcelona, 2000, p. 134.

14 BRUFAL SUCARRAT, J., El món rural i musulmà en la Lleida musulmana (s. XI-XII). Lleida i l'est del districte: Castelldans i el pla del Mascançà, Lleida, 2013 (en premsa). 
El ámbito territorial nororiental y oriental lo denominamos la frontera extrema, por ser el último sector donde aun se identifica la ocupación organizada y explotación del paisaje por parte de la sociedad andalusí15. A sus espaldas, restan resguardadas las fértiles llanuras leridanas del Fahs Maškiğḡan y la Llitera -respecto este topónimo, que hoy es una entidad administrativa local de Aragón, el historiador Josep Lladonosa identificó su raíz procedente del nombre de la capital, Lārida ${ }^{16}-$. Mientras, el área meridional estaba protegida por la fortificación de Castelldans ${ }^{17}$, y la ciudad de Fraga. Con ésta descripción pretendemos ofrecer una estratigrafía territorial del distrito leridano, donde, el tejido organizativo de asentamientos rurales en la frontera lo estabiliza, propiciando que en la cronología del siglo x la medina sea el motor social y económico, y articule áreas agrarias de los peligros exteriores ${ }^{18}$.

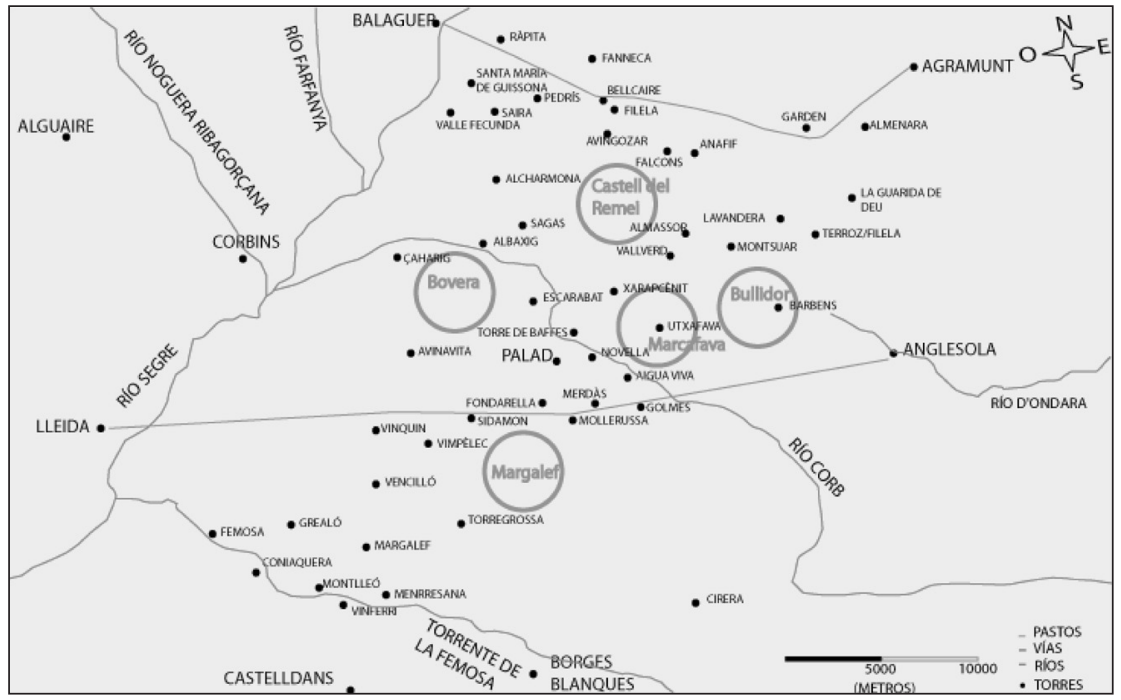

Mapa con los asentamientos andalusíes del pla del Mascançà.

15 SABATÉ CURULL, F., Atles de la "Reconquesta". La frontera peninsular entre els segles VIII $i$ XV, Barcelona, 1998, p. 15.

16 LLADONOSA PUJOL, J., Els carrers i places de Lleida a través de la història, Lleida, 2007, p. 588, 840.

17 BRUFAL SUCARRAT, J., L'espai rural del districte musulmà de Lleida (segles XI-XII). Espais de secà meridionals, www.tdx.cat, Lleida, 2008.

18 BRUFAL SUCARRAT, J., El món rural i musulmà en la Lleida musulmana (s. XI-XII). Lleida i l'est del districte: Castelldans i el pla del Mascançà, Lleida, 2013 (en premsa). Sobre el terreno, el Faḥs Maškīğān alberga cincuenta y dos asentamientos (agropecuarios y fortificaciones), y el área de Castelldans, en el sureste del distrito treinta y seis (también entre agropecuarios y fortificaciones). 
Los datos aportados hasta el momento únicamente indican la identificación de áreas limítrofes, pero no se ha profundizado en el propio estudio de ¿por qué etiquetamos estos ámbitos como frontera? Bien, el proyecto emiral de organizar la Frontera Superior, y en concreto, el distrito leridano, nace como consecuencia de la conquista de Barcelona el 801 y el empuje de los carolingios más allá del pre-Pirineo y de los ríos Llobregat y Cardener ${ }^{19}$. Dicha respuesta emiral se concretiza con la consolidación de un amplio espacio de vanguardia plenamente organizado, donde la sociedad andalusí lo ocupaba y lo explotaba.

¿Por qué se escogieron como límites "extremos" las cabeceras de los ríos Llobregós, Sió, Ondara, Cercavins y Corb? Consideramos que la respuesta recae en tres ítems: un ámbito social organizado por población de tradición hispano-romana, las vías de comunicación, y la capacidad de obtener recursos del medio natural. Así pues, durante el siglo octavo la zona de estudio era des de la óptica andalusí o bien un lugar de paso -nos referimos a la vía romana que comunicaba Lleida y Barcelona resiguiendo el curso del río Corb- ${ }^{20}$, o bien, meros espacios agropecuarios ocupados por población hispano-visigoda -el ager de Aesso. Durante el siglo octavo el territorio leridano tuvo una escasa trascendencia en el organigrama administrativo del incipiente estado andalusí. Lárida desarrollaba funciones de base militar durante las campañas hacia el norte franco o para combatir alzamientos de gobernadores poco afines al poder cordovés. De estas destaca la expedición de castigo de 'Abd al-Rahmān b. 'Abd Al-lāh al-Gāfiqī contra Munūsa, gobernador beréber de Narbona ${ }^{21}$. Esto propició que la sociedad de tradición hispano-visigoda siguiese manteniendo el modelo de ocupación y explotación, hasta el punto que en el caso de Aesso, la arqueología ha dado luz a la perduración de ritos funerarios cristianos, y la más que probable consolidación del espacio sagrado que representaba la iglesia, en el centro de la villa ${ }^{22}$. En el yacimiento arqueológico de Santa Coloma (Àger, Lleida), necrópolis que se ubica en el sector central de la frontera andalusí del distrito de Lleida, las excavaciones arqueológicas y, los estudios bioarqueológicos, aportan datos referentes a la población allí ihumada, destacando el ritual cristiano de enterramiento y el uso de este espacio sagrado se prolongo desde

19 SABATÉ CURULL, F., Història de Lleida. Alta edat mitjana, Lleida, 2003, pp. 25-28.

20 BENET CLARÀ, A., "La repoblación del comte Guifré", Catalunya Romànica, vol. XXIV, Barcelona, 1994, p. 301. LÓPEZ MELCIÓN, J., "La romanització i el món romà", Catalunya Romànica, vol. XXIV, Barcelona, 1994, p. 300.

21 BRAMON PLANES, D., De quan érem o no musulmans. Textos del 713 al 1010, Barcelona, 2000, pp. 161.

22 LÓPEZ MELCIÓN, J., "La romanització i el món romà", Catalunya Romànica, vol. XXIV, Barcelona, 1994, p. 300. 
el siglo V hasta el siglo $\mathrm{XI}^{23}$. Por lo tanto, señalamos este dato como trascendental para entender la rápida consolidación de la frontera andalusí en éste ámbito territorial. Además se corrobora la consolidación del proceso de integración de los sustratos sociales autóctonos dentro de una sociedad, que se encuentra en claro proceso de arabización. El ager de Aesso, además, contempla interesantes topónimos Palol, Palouet ${ }^{24}$.

La cohesión interna de un distrito depende en buena medida de la capacidad de comunicarse por vía terrestre y/o fluvial. Éste dato se confirma durante los cuatro siglos de cultura andalusí en Lleida, desde las expediciones militares resiguiendo el río Segre hacia territorio condal en los siglos IX y $\mathrm{X}^{25}$, la expedición de socorro hacia la ciudad de Fraga del 1134 encabezada por Ibn Ganiya gobernador de Valencia, hasta convertir las vías de comunicación en complementos de los espacios productivos -nos referimos al movimiento de rebaños en el Fahs Maškīğān, en búsqueda de los marj pastos comunales ubicados en espacios óptimos para la regeneración de la flora.

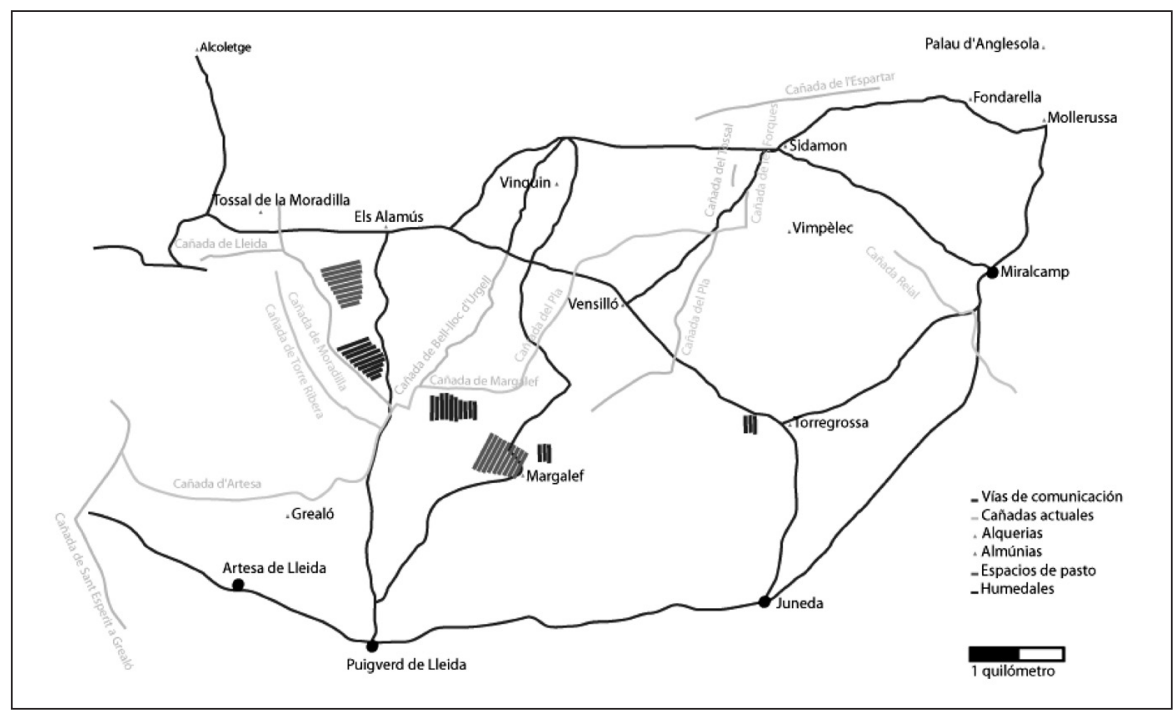

Mapa de las cañadas actuales en relación con el marj actual Margalef.

23 Las excavaciones arqueológicas y los estudios bioarqueológicos los dirigen el profesor Lector Jesús Brufal Sucarrat (UAB), la investigadora predoctoral Àngela G. Centelles (UdL) y la investigadora predoctoral Júlia Olivé Busom (UAB).

24 COROMINES VIGNEAUX, J., Onomasticon Cataloniae. Els noms de lloc i noms de persona de totes les terres de llengua catalana, VI, Barcelona, 1988, pp. 144-145.

25 BRAMON PLANES, D., De quan érem o no musulmans. Textos del 713 al 1010, Barcelona, 2000, doc. 81, p. 185. 
Si focalizamos la atención en el área de estudio, las vías de comunicación son determinantes, pues citamos la ya mencionada vía romana entre Lleida y Barcelona, y además resaltamos el espacio transitable de los valles fluviales de los ríos Llobregós, Sió, Ondara, Cercavins y Corb. Éstos, nacen en el Altiplano de la Segarra y dirigen sus aguas hacia el llano de Lleida, trazando un eje transversal E-O. La morfología de éstos valles fluviales es óptima para la circulación de personas, mercancías, ganados, y tropas, pues son cuencas anchas y sin apenas dificultades orográficas.

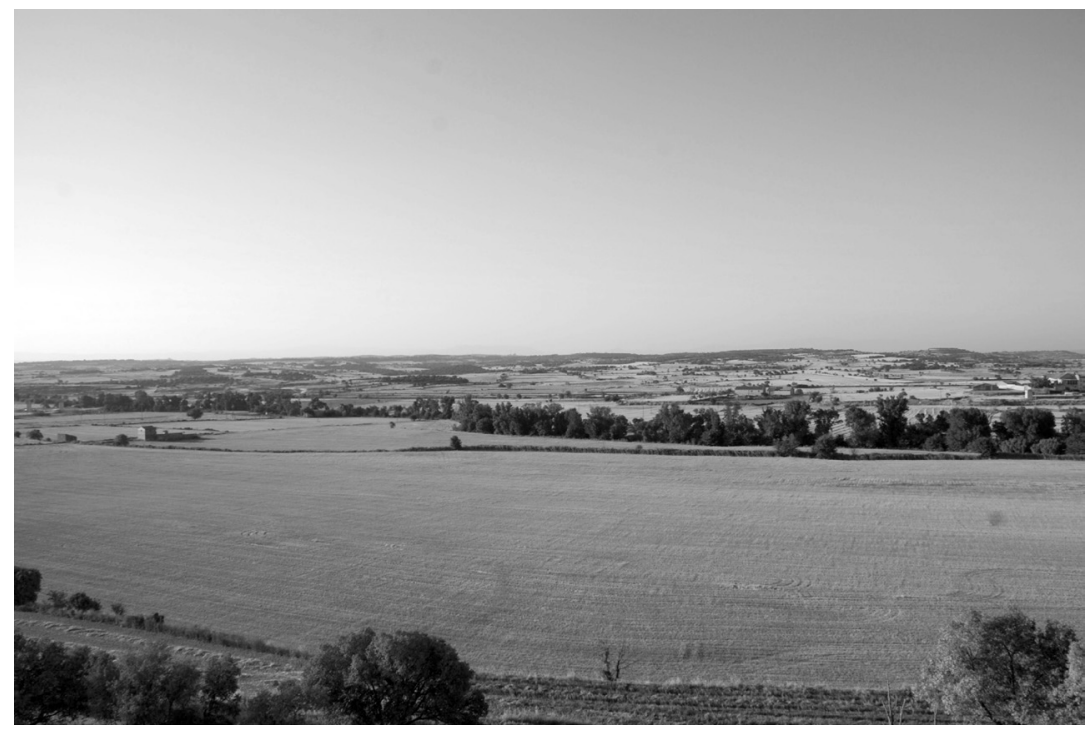

Foto del río Sió en su paso por el municipio de Plans de Sió.

De este modo, se puede circular desde Aesso hacia el río Segre resiguiendo el río Llobregós, para conectar con una de las principales vías de penetración hacia los Pirineos.

Este eje, es sin lugar a dudas de gran importancia para mantener la cohesión de la frontera nororiental, pues el movimiento de tropas en este sector es relativamente fácil y rápido. Paralelamente desde Aesso y resiguiendo el valle del río Sió se articula el espacio paralelo al anterior que mencionábamos, con el añadido que el Sió desemboca al Segre en las puertas de Balaguer. Por lo tanto, las vías de comunicación resiguiendo los cursos fluviales y partiendo desde Aesso dibujan un triangulo comunicativo (Aesso-Ponts-Balaguer-Aesso) que articula este amplio sector de la frontera leridana. Albert Benet ya advirtió del itinerario probable de las tropas andalusíes por la frontera, resiguien- 


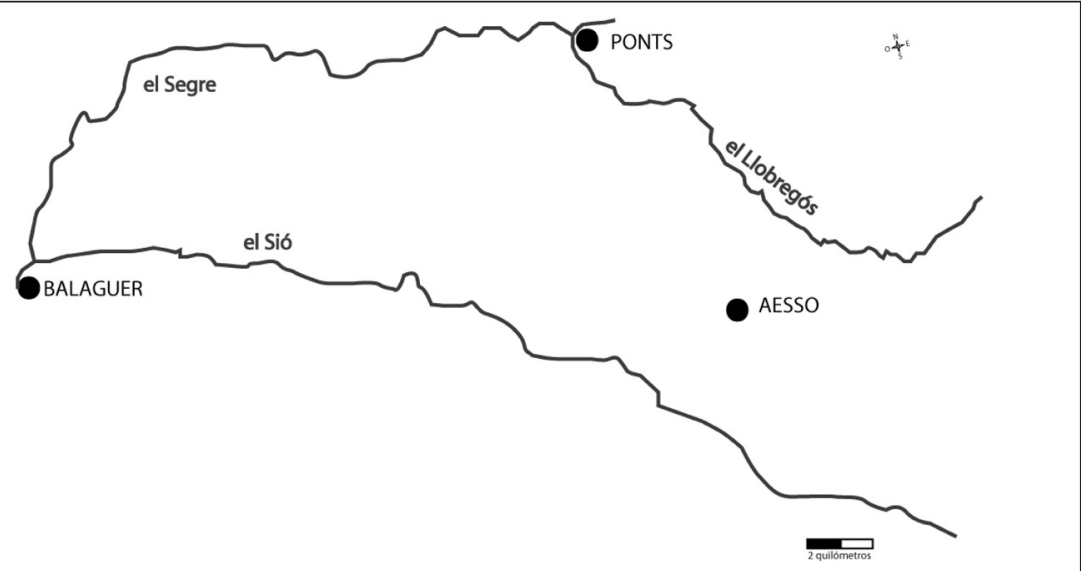

Mapa con los ríos Segre, Sió y Llobregós, y la ubicación de los asentamientos de Balaguer, Aesso y Ponts.

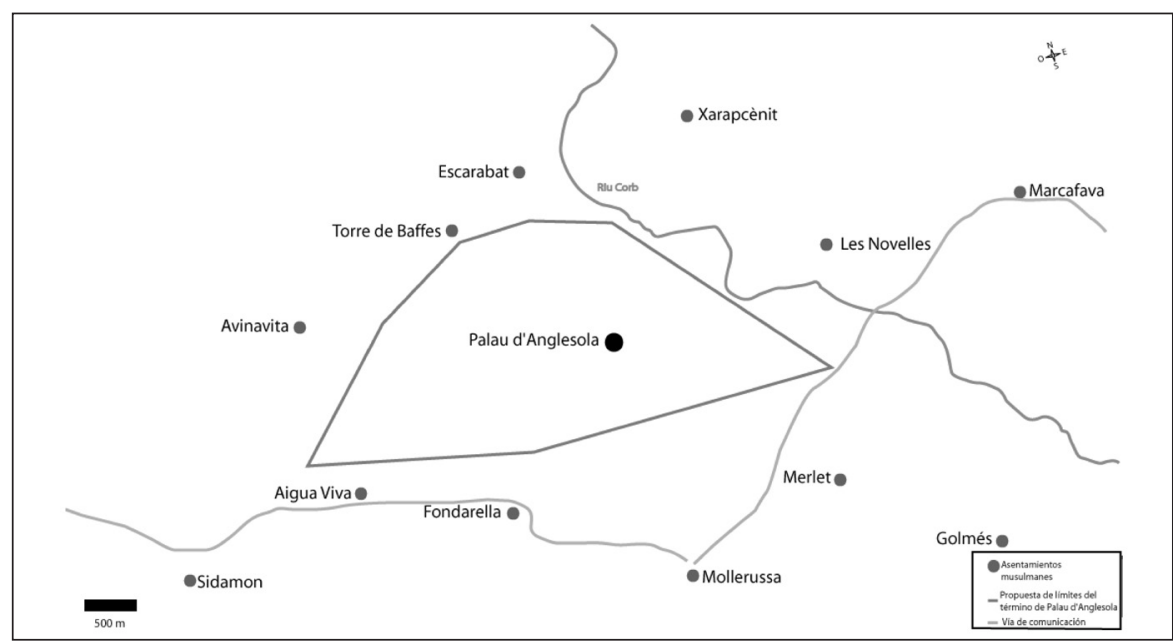

Mapa con la propuesta de límites del término medieval de Palau d'Anglesola.

do el valle del Segre hasta Ponts y luego hacia el este a través del valle del río Llobregós hasta alcanzar Calaf y, desde aquí asaltar la Cuenca del Òdena ${ }^{26}$, donde allí murió un personaje, Audesind, como consecuencia de un ataque ${ }^{27}$.

26 BENET CLARÀ, A., El procés d'independència de Catalunya (897-989), Sallent, 1988, p. 124-126).

27 RIUS SERRA, J., Cartulario de Sant Cugat del Vallés, Barcelona, 1945-1947, vol. 2, doc. 381). 


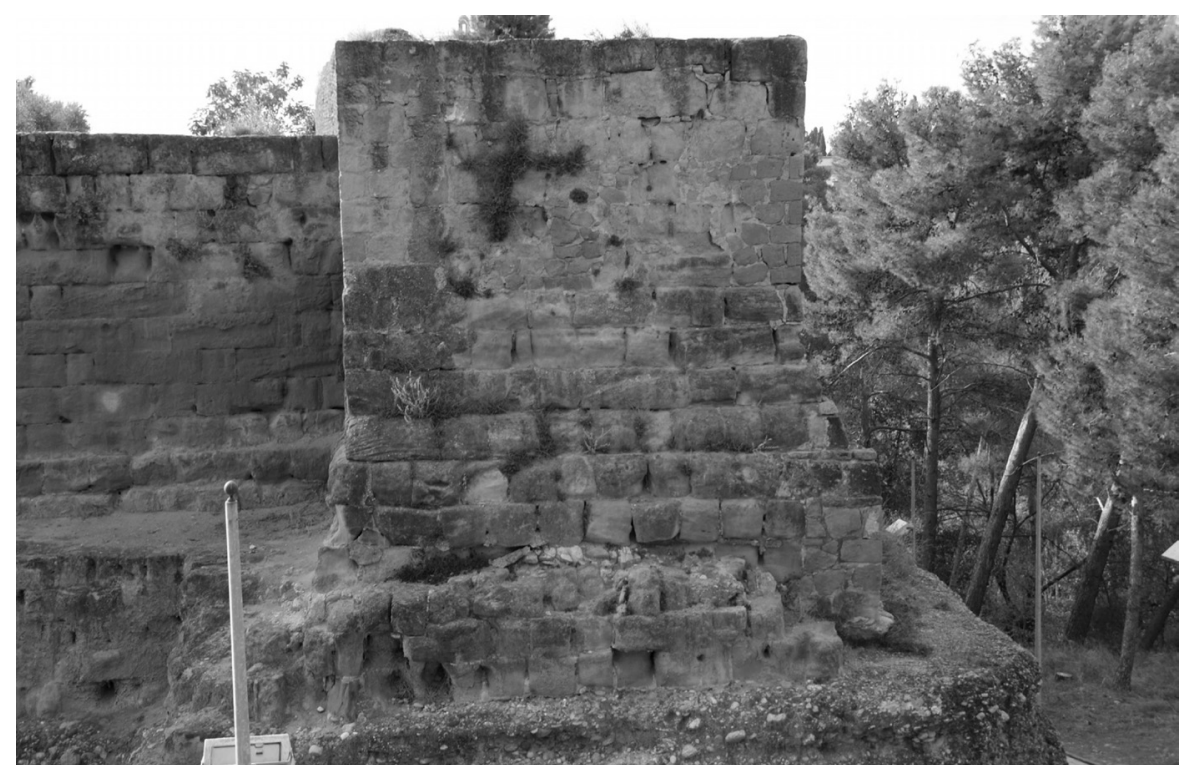

Torre del Castell Formós (Balaguer).

Además, el territorio del sector oriental, también se comunica a partir de los ríos Ondara, Cercavins y Corb cuyos valles fluviales se convierten en tres importantes vías de comunicación. En las proximidades de estos ríos teje una fluida red de asentamientos todos ellos bien comunicados, para afrontar las posibles adversidades provenientes del espacio condal. Así pues, resiguiendo las riberas de los ríos Sió, Ondara, Cercavins y Corb y, con los datos de la documentación latina de los siglos XI y XII, se trazan polígonos de relación y producción entre asentamientos y los cursos fluviales, desde el extremo fronterizo del distrito, el Fahs Maškĭğān, y la ciudad de Lleida ${ }^{28}$. Entre Tàrrega y Lleida, discurre una vía de comunicación que participa en la articulación de la vertiente oriental y central del distrito leridano -importante fortificación que une el espacio fronterizo oriental y el Fahs Maškiğăn-. En sus alrededores se ubican numerosos asentamientos, todos ellos ubicados dentro del Fahs Maškĭğān, requieren especial mención la "torre de Molleruza" "Palad et Alfandarella", "Aigua Viva", "Torre Roga". ${ }^{29}$

28 Liber Feudorum Maior: cartulario real que se conserva en el Archivo de la Corona de Aragón, ed. Francisco Miquel Rosell, Barcelona, 1945-1947, doc. 165, p. 174.

29 SAROBE, R., Col.lecció diplomàtica de la Casa del Temple de Gardeny (1070-1200), Barcelona, 1998, doc. 14, p. 98. Es sugerente resaltar que la conquista condal de estos sectores se inmiscuye precisamente, siguiendo las vías de comunicación que estamos explicando. Es el caso del condado de Barcelona que resiguiendo el río Corb entra al 
Por su parte, el medio natural presenta unas óptimas condiciones para la explotación agropecuaria. Los estudios edafológicos sitúan los mejores espacios para la agricultura en las inmediaciones de los cursos fluviales ${ }^{30}$. Las características de los valles fluviales, favorecen la explotación agropecuaria, haciendo hincapié en la agricultura de irrigación. En las inmediaciones de estos valles fluviales se extienden llanuras áridas ${ }^{31}$, aprovechadas para los cultivos de secano. Esto incide directamente en los espacios de secano y su explotación productiva ${ }^{32}$. El aprovechamiento del agua se convierte en la principal prioridad de los asentamientos agropecuarios, construyendo sistemas hidráulicos en las inmediaciones de los cursos fluviales, es el caso del "reger de Exercavinos". 33

\section{CONFIGURACIÓN DEL PAISAJE ANDALUSÍ FRONTERIZO EN EL NORESTE Y ESTE DEL DISTRITO DE LLEIDA}

La configuración del paisaje andalusí fronterizo en el distrito de Lleida se estudiará desde tres ejes primordiales: los asentamientos agropecuarios, la protección y la seguridad, y la religión.

La estabilización de la frontera nororiental y oriental del distrito leridano es consecuencia de la perduración de un sustrato autóctono rural, y la iniciativa andalusí de colonizar la frontera. El reflejo de estas acciones en el paisaje es por mediación de asentamientos agropecuarios que se distribuyen en las inmediaciones o proximidades de los cursos fluviales de los ríos Llobregós, Sió, Ondara, Cercavins y Corb. Estos asentamientos se construyen pensando en tres prioridades: la protección, el espacio doméstico y el espacio productivo. La protección como se verá más adelante, se representa con una torre de base cuadrada de factura en sillarejo como es visible en la Guàrdia de Déu, y/o refugios subterráneos conocidos por al-Himyar̄̄ y al-Qazwīn̄̄ como sirdab. El estado de la investigación no ha permitido localizar con certeza los espacios domésticos y de producción de los asentamientos agropecuarios andalusíes.

Fahs Maškĭğān por el sureste. Estas vías comunican los principales sectores productivos del Mascançà, destacando además el asentamiento de Barbens.

30 Consultar la página web: http://www.iec.cat/mapasols/Ca/CercarMunicipis. asp? Grup=E\&Opcio $=13$

31 Al-Himyarī describía que "la ciutat de Lleida és fértil malgrat la sequedat [dels seus voltants], BRAMON PLANES, D., De quan érem o no musulmans. Textos del 713 al 1010, Barcelona, 2000, doc. 48, p. 86.

32 BRUFAL SUCARRAT, J., "Els espais de secà", Arqueologia Medieval. Els espais de secà, Lleida, 2011, pp. 9-18.

33 AlTISENT ALTISENT, A., Diplomatari de Santa Maria de Poblet (960-1077), Abadia de Poblet, doc. 84 , p. 87. 
La protección y seguridad de las comunidades rurales se configura a partir de las torres que se construyen en los asentamientos agropecuarios, las torres de vigilancia y pequeñas fortificaciones. El asentamiento agropecuario de Vilagrasseta (Plans de Sió, Lleida), estaba protegido por una torre de base cuadrangular, construida con sillares que imitan la técnica a soga y tizón con disposición irregular.

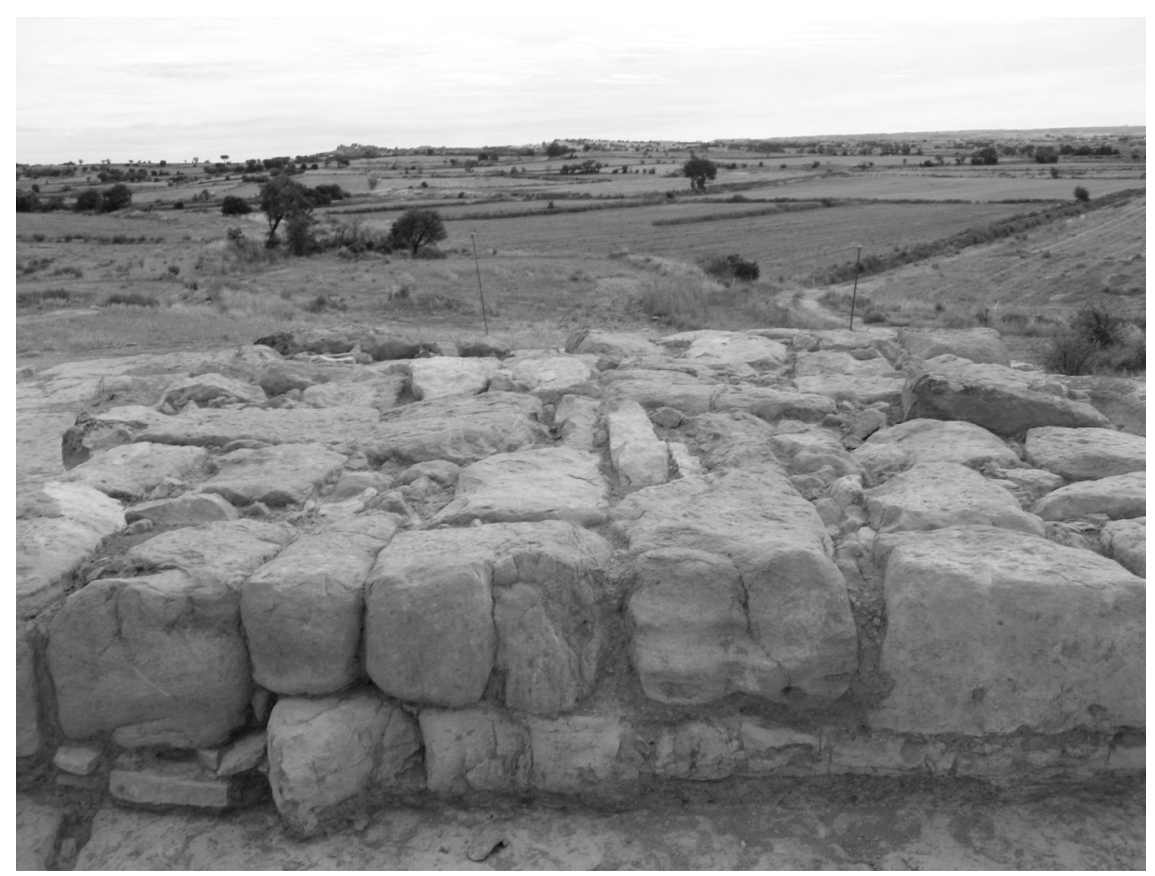

Torre de Vilagrasseta (Plans de Sió).

En las inmediaciones de la torre se han localizado diversos enterramientos que corresponden a la tipología "tumbas antropomorfas excavadas en la roca", de ritual cristiano. La duda que tenemos es si las tumbas coexisten con la torre andalusí por lo tanto hablaríamos de población cristiana en un contexto político andalusí, o simplemente corresponden a distintas fases. Los resultados de los trabajos arqueológicos confirman que la torre es de nueva fundación y contextualizada, como hemos apuntado, en el período andalusí pero sin poder precisar una cronología (s. IX-X). Éste tipo de torres de características más reducidas las asociamos o bien a una pequeña alquería o a una almunia. Su función era proteger los habitantes de dichas tipologías de asentamientos, y descartamos la vocación ofensiva. 
Una segunda tipología de torres son las de vigilancia y que únicamente reconocemos por sus topónimos: la "cirera" y almenara. Referente al topónimo "cirera" lo localizamos en el extremo de la frontera, en un punto elevado del curso inicial del río Corb, y que actualmente es un pequeño núcleo que conserva el mismo nombre (la Cirera, Tarragona). Más hacia el este y en la población de Guimerà se localiza otro topónimo "cirera", también ubicado en altura para garantizar una óptima visión del valle fluvial. Pere Balañà relaciona éste topónimo con el vocablo árabe siraj que significa hacer señales luminosas ${ }^{34}$. Similarmente, el topónimo almenara lo encontramos en el límite septentrional del Fahs Maškīğān, ubicado en altura para garantizar un óptimo control del espacio fronterizo y del interior del distrito.

Una tercera tipología de torres son las que detectamos en Concabella y Palou (ambas en Lleida). Son edificios de mayor tamaño que las torres anteriores, su planta es ligeramente rectangular y se construyen con sillares a soga y tizón con disposición irregular, y sin apreciar el tapial. Su ubicación en la frontera extrema les otorga un carácter militar. La ausencia de trabajos arqueológicos en estas fortificaciones dificulta el proceso de estudio, y desconocemos si en el período histórico precedente había ocupación. En el caso de Palou, quizá, teniendo en cuenta el topónimo Palou ${ }^{35}$, podríamos seguir un hilo de ocupación tardoantigua, pero es bastante incierto. Respecto Aesso es un asentamiento singular, pues los trabajos arqueológicos no han localizado restos de elementos arquitectónicos defensivos del periodo andalusí.

Su capacidad defensiva les otorgaría un papel vertebrador de un propio espacio, entendido como una unidad representante de la ciudad y del poder emiral en la novena centuria, y califal en la décima centuria. Esto significa que podrían controlar la fiscalidad de un área con diversos asentamientos agropecuarios. De ser así, el ager de Aesso de herencia tardoantigua se fragmentó, pues Palou, de corroborarse su ocupación en éste período, desarrollaría un papel vertebrador de un propio espacio. No obstante, a fecha de hoy no podemos aportar datos fidedignos respecto a qué respondía la organización de estos microespacios encabezados por una torre de mayor magnitud. En 1015 el obispo Borrell da al levita Guillem una tierra que incorpora tres cerros, Kalafum, Kalafellum y Ferraria ${ }^{36}$. Este topónimo hoy se identifica con

34 BALAÑ̃̀ ABADIA, P., "Les "cireres" en l'estratègia defensiva andalusina en la frontera superior", Revista d'Igualada, 12, 2002, pp. 7-11.

35 COROMINES VIGNEAUX, J., Onomasticon Cataloniae. Els noms de lloc i noms de persona de totes les terres de llengua catalana, VI, Barcelona, 1988, pp. 144-145.

36 FONT I RIUS, J.M., Cartas de población y franquícia de Cataluña, Madrid-Barcelona, 1969, vol. 1, p. 23-25). 
el municipio de Calaf (Barcelona), un nombre que se relaciona con la palabra árabe Qal'at (fortaleza).

Ante la evidencia del nombre, esta contrasta con los datos arqueológicos obtenidos de las excavaciones allí realizadas por Jesús Brufal Sucarrat: hasta el momento no hay evidencias materiales de contexto andalusí. El contexto geográfico de Calaf es muy interesante para comprender este sector de la frontera, pues muy cerca nace el río Llobregós, curso fluvial que articula el extremo nororiental del distrito andalusí de Lleida, hasta desembocar sus aguas al río Segre en Ponts, otra fortaleza andalusí. Hacia el oeste, Calaf prácticamente alcanza el ager de Guissona. A falta de más arqueología, este asentamiento fortificado formaba parte de la frontera andalusí ante los condados de Osona y Manresa.

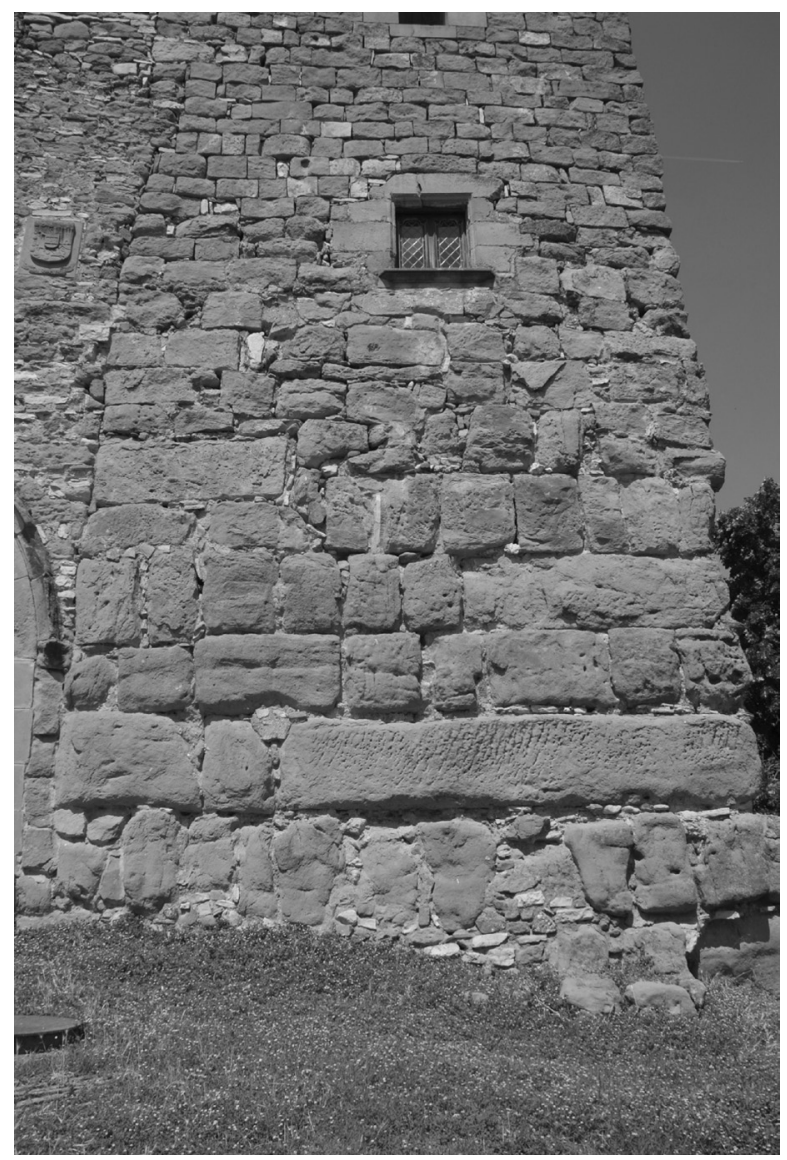

Torre de la Ràpita (Vallfogona de Balaguer). 
La religión en la frontera extrema la detectamos por mediación del concepto ràbita. En sus estudios sobre la proyección del condado de Manresa sobre el distrito leridano, Albert Benet plantea que la actual población de Rubinat (Lleida), se llamó hasta hace relativamente poco (s. XIX), rabinat ${ }^{37}$. Es una propuesta interesante que debe estudiar-se de nuevo. No obstante, cerca de Balaguer se ha conservado el topónimo Ràpita y una imponente torre defensiva, de planta rectangular alzada con gran sillar de piedra defensiva, de planta rectangular alzada con gran sillar de piedra ${ }^{38}$.

\section{CONCLUSIÓN}

La frontera nororiental y oriental del distrito de Lleida no es un espacio desértico. La línea fronteriza trazada por los Banú Qasí en el transcurso del siglo IX en los ríos Llobregós y las cabeceras del Sió, Cercavins y Corb, favoreció la organización de un espacio social de frontera, claramente integrado en un distrito andalusí articulado desde la ciudad y su gente. La población autóctona es presente en todo el distrito leridano, y concretamente en el área de estudio. El precedente tardoantiguo ha condicionado a favor de vertebrar todo éste amplio sector territorial. La sociedad leridana fundamenta su identidad en la religión, la defensa y la explotación agropecuaria.

37 BENET CLARÀ, A., "La repoblación del comte Guifré", Catalunya Romànica, XXIV, Barcelona, 1994, pp. 301-302.

38 BRUFAL SUCARRAT, J., Les ràpites. Proposta de definició conceptual a partir del cas del nord-est peninsular, Lleida, 2008. 